\title{
A escola como espaço revelador da violência doméstica contra a criança: um estudo de caso
}

\author{
School as a revealing space of domestic violence against \\ children: a case study
}

\section{La escuela como espacio revelador de la violencia doméstica contra la infancia: un estudio de caso}

\author{
Maria Aparecida da Silva \\ http://orcid.org/0000-0001-8178-2929 \\ Maria do Horto Tiellet \\ http://orcid.org/0000-0002-1794-7271 \\ Vivian Lara Cáceres Dan \\ http://orcid.org/0000-0001-9880-3028
}

\begin{abstract}
Resumo: O presente estudo tem como objetivo tipificar a violência contra a criança em âmbito familiar e saber de que forma a escola trabalha com o problema. Utilizamos como suporte teórico-metodológico a abordagem fenomenológica, e como instrumento de pesquisa a entrevista. Nove foram os sujeitos escolhidos pela técnica da "cadeia de informantes", iniciada pelo/a diretor/a da escola. A violência doméstica contra a criança, analisada a partir do olhar dos sujeitos significativos, manifesta-se pela negligência, pela violência física, pelos maus tratos, pelo abuso sexual e o estupro relatados por mães e agressores/as identificados/as, mas não são denunciados/as, quer seja pela escola ou pelos/as responsáveis pela criança. Em relação ao que foi constatado, é possível afirmar que, no âmbito escolar pesquisado, as ações para o enfrentamento do problema da violência contra crianças e adolescentes são ineficazes, inúteis, e não surtem efeito.
\end{abstract}

Palavras-Chave: Professor. Violência doméstica contra a criança. Violência intrafamiliar.

\begin{abstract}
This piece of study aims to define violence against children within the family, and to understand how school copes with the problem. As a theoretical-methodological input, we used a phenomenological approach. Our research tool was the interview. Nine subjects were chosen by applying the "chain of informants" technique, starting with the school principal. Domestic violence against children, as analyzed from the point of view of significant subjects, is portrayed by neglect, physical violence, maltreatment, sexual abuse and rape reported by both mothers and identified perpetrators. However, they are not reported either by the school nor by those who are responsible for the children. Regarding to what has been found out in the researched school setting, one can affirm that actions to cope with the problem of violence against children and adolescents are ineffective, worthless and do not work.
\end{abstract}


Keywords: Phenomenology. Teacher. Domestic violence against children. Intrafamily violence.

Resumen: El presente estudio tiene como objetivo tipificar la violencia contra la infancia en el ámbito familiar y saber de qué forma la escuela aborda el problema. Utilizamos como soporte teórico-metodológico la perspectiva fenomenológica, y como instrumento de investigación, la entrevista. Fueron entrevistados 9 sujetos seleccionados a partir de la "cadena de informantes", iniciada por el/la director/a de la escuela. La violencia doméstica contra los niños según análisis desde la mirada de los sujetos significativos se manifiesta por la negligencia, la violencia física, los malos tratos, el abuso sexual y la violación reportados por madres y por agresores/as identificados/as. Sin embargo, no son denunciados/as por la escuela tampoco por los/as responsables de los niños. En relación con lo constatado, se puede afirmar que, en el ámbito escolar investigado, las acciones al enfrentamiento del problema de la violencia contra los niños y adolescentes son ineficaces, inútiles y no surten efecto.

Palabras-clave: Fenomenología. Profesor. Violencia doméstica contra la infancia. Violencia intrafamiliar

\section{Introdução}

Iniciamos com a afirmação de Azevedo e Guerra (2009) de que a violência doméstica contra a criança no "país, tem de se apoiar em dados de pesquisa, assim como em relatos de casos, depoimentos e outras fontes". (p.15)

[...] o Brasil não mantém estatísticas oficiais sobre casos notificados de violência doméstica contra crianças e adolescentes, assim como não realiza estudos sistemáticos sobre incidência e prevalência do fenômeno, e que o tradicional complô de silêncio sempre cercou essa modalidade de violência [...]. (AZEVEDO; GUERRA, 2009, p.16).

A temática violência doméstica tem construído um campo de discussões bastante amplo na atualidade, pois é entendida como a aplicação da força e do uso de condições privilegiadas de um sujeito sobre o outro, isto é, a violência doméstica constitui-se em um fenômeno complexo que envolve aspectos relacionados às questões familiares caracterizando abuso de poder nas relações.

A violência doméstica é aquela que envolve pessoas com as quais se têm laços afetivos ou de parentesco e que ocorre paradoxalmente, nos espaços das relações familiares, onde do ponto de vista social, seria os lócus privilegiados de amor, proteção e solidariedade. (WEBER, 2005, p. v)

A violência doméstica acompanha a trajetória humana, e, nesse sentido, se constitui em um fenômeno complexo que se relaciona com normas sociais e costumes de determinadas épocas e locais, produzindo consequências em todos os espaços da sociedade, pois se integra ao cotidiano das famílias.

No âmbito doméstico, a violência se estabelece mediante uma relação de poder com a vítima, de modo que o agressor pode ser qualquer membro da família ou de parentesco 
hierarquicamente superior; e a vítima, subordinada financeira ou emocionalmente, pode ser qualquer membro da família - idoso, mulher, criança ou adolescente.

Atualmente, a violência doméstica é considerada um grave problema de saúde pública, considerando-se a forma disseminada e intensificada com que tem se apresentado, principalmente em relação à criança. Isso não significa que a violência contra a mulher, o idoso, ou que envolva discriminação de gênero, seja menos significativa. Com certeza não é, mas aqui se trata de crianças, da fragilidade da vítima que tem, no seio da família, o local de sua proteção e cuidado. É o uso da força física ou psicológica sobre um sujeito frágil, com potencial de vulnerabilidade e dependência dos adultos que nos deixa perplexos.

Esforços internacionais orientam para a preservação dos direitos das crianças e para a prevenção do maltrato infantil, criando-se agências governamentais e não governamentais - ONG. Várias ONGs foram instituídas, em diversas partes do mundo, no intuito de lançar um olhar de proteção à criança e buscar sensibilizar os governos para a criação de leis de proteção, pois a violência contra a infância acontece em nível mundial, e está presente em todas as culturas, faixa de renda, níveis de escolaridade e grupos étnicos.

Em 1983, várias organizações não governamentais foram criadas em defesa dos direitos das crianças. As ONGs que saíram em defesa das crianças, mantidas ou criadas no âmbito global, foram, a Sociedade Internacional para a Prevenção do Abuso e Negligência contra as Crianças (ISPANC), e a Childhood Brasil ${ }^{1}$ entre outras.

No ano de 2006, o Secretário-Geral das Nações Unidas divulgou aos membros da Assembleia Geral o Relatório do especialista Paulo Sérgio Pinheiro, intitulado Estudo das Nações Unidas sobre a Violência Contra Crianças. De acordo com o autor, era o primeiro estudo abrangente e global desenvolvido pelas Nações Unidas sobre todas as formas de violência contra crianças, e "também o primeiro estudo global que envolveu crianças diretamente em todo o processo de sua elaboração". (PINHEIRO, 2006, p.5).

Em 1989, a Convenção sobre os Direitos da Criança foi aprovada pela Assembleia Geral da ONU e aberta à subscrição e ratificação por parte dos Estados membros.

A violência contra a criança não pode ser justificada pela tradição ou como forma de disciplinar um ser humano, afirma Pinheiro (2006):

Nenhum tipo de violência contra crianças é justificável; todas as formas de violência contra crianças podem ser prevenidas. No entanto, o estudo detalhado sobre a violência contra crianças (doravante, o Estudo) confirma que esse tipo de violência ainda prevalece em todos os países do mundo e está presente em todas as culturas, classes, níveis de escolaridade, faixas de renda e origens étnicas. Em todas as regiões, contradizendo obrigações de respeito aos direitos humanos e às necessidades de desenvolvimento da criança, a violência contra crianças é um fenômeno

1 É uma organização nacional que faz parte da World Childhood Foundation, criada por S.M. Rainha Silvia da Suécia. Fundada em 1999, a Childhood Brasil desenvolve ações para a proteção e o desenvolvimento integral de crianças e adolescentes. No Brasil, a organização trabalha com foco no enfrentamento do abuso e da exploração sexual de crianças e adolescentes (CHILDHOOD, 2004, p.7) 
socialmente aprovado e frequentemente legal e autorizado pelo Estado. (PINHEIRO, 2006, p. 5).

O Fundo das Nações Unidas para a Infância (Unicef) aponta que apenas 59 países adotam legislação que proíbe, de forma definitiva, o uso de castigos físicos ${ }^{2}$ contra crianças.

Em 2017, o relatório do Fundo das Nações Unidas para a Infância (Unicef) - Um rosto familiar: a violência na vida de crianças e adolescentes - revela que a cada sete minutos uma criança ou adolescente morre vítima de violência no mundo. Em 2015, mais de 82 mil jovens, entre 10 e 19 anos, morreram vítimas de homicídios, de conflito armado ou violência coletiva, destacando que os índices mais altos se concentram na América Latina e Caribe, e que o Brasil está entre aqueles que possuem as taxas mais altas de homicídio do mundo.

No Brasil, a partir de 1990, foram reconhecidos os maus tratos às crianças como uma questão pública. Segundo dados do Conselho Nacional dos Direitos da Criança e dos Adolescentes (BRASIL,2000³, anualmente, 6,5 milhões de crianças e adolescentes sofrem algum tipo de violência doméstica ${ }^{4}$, e esses mesmos dados também apontam que 18 mil crianças são espancadas diariamente, e 300 mil crianças e adolescentes são vítimas de incesto. No relatório - Um rosto familiar: a violência na vida de crianças e adolescentes (2017) - o Brasil, na lista de países sem conflito armado, embora tenha lei de proteção à criança e ao adolescente, aparece com a quinta maior taxa de homicídios de crianças e adolescentes do sexo masculino, com idade entre 10 e19 anos.

A violência contra crianças assume diversas formas e é influenciada por uma ampla gama de fatores, que envolvem desde as características pessoais da vítima e do agressor até seu ambiente cultural e físico. No entanto, grande parte da violência contra crianças continua camuflada por muitas razões. Uma delas é o medo: muitas crianças têm medo de denunciar incidentes de violência contra elas. Em muitos casos, os pais, que deveriam proteger seus filhos, permanecem em silêncio se a violência for cometida por um cônjuge ou outro familiar, um membro mais poderoso da sociedade, como um empregador, um policial ou um líder comunitário. [...] O estupro ou outras formas de violência sexual podem, particularmente, gerar ostracismo, mais violência ou morte. (PINHEIRO, 2006, p.9)

Grande parte das crianças vítimas de violência frequenta a escola - pública ou privada - e, muitas vezes, apresenta comportamentos incompreendidos por parte dos educadores.

2 No Brasil, o castigo físico foi proibido pela Lei n.13.010 de 2014, conhecida como Lei Menino Bernardo.

3 O Conselho Nacional dos Direitos da Criança e do Adolescente - Conanda - é um órgão colegiado permanente, de caráter deliberativo, previsto no artigo 88 da Lei no 8.069/90 - Estatuto da Criança e do Adolescente (ECA). Integra a estrutura básica da Secretaria de Direitos Humanos da Presidência da República (SDH/PR).

4 A violência doméstica pode ser subdividida em violência física, psicológica, sexual, patrimonial e moral e o abuso sexual. 
Para Guerra (2007), crianças com baixo rendimento escolar, apáticas, com atitudes violentas, baixa autoestima merecem um olhar mais atento do/a professor/a, pois estes são alguns dos sinais que podem indicar ocorrências de violência doméstica.

O Brasil foi um dos primeiros países do mundo e o primeiro da América Latina a criar um estatuto que atendesse as normativas internacionais no que diz respeito à proteção das crianças e adolescentes, proibindo e condenando a violência infantil. A Constituição Federal (CF) e o Estatuto da Criança e Adolescente (ECA) determinam como dever de todos família, sociedade e Estado assegurarem à criança e ao adolescente um desenvolvimento saudável, evitando todas as formas de discriminação e opressão, ou seja, de quaisquer formas de violência.

O ECA é uma lei complementar de n. 8.069/1990 que traz dispositivos específicos sobre os direitos das crianças e adolescentes no seu artigo $4^{5} \mathrm{e}$ sobre punição à violência infantil no seu artigo $5^{6}$. Esses dispositivos podem ser utilizados para dar assistência à população infanto-juvenil vítima de violências ou omissão em relação a seus direitos. $E$ "as estatísticas revelam que as crianças e os adolescentes vivenciam a violência em todas as fases da infância e da adolescência, em diversas configurações, e frequentemente pelas mãos de pessoas em quem confiam e com quem interagem diariamente." (ONU, 2017, p.1).

\section{Um fenômeno: a violência doméstica contra criança em idade escolar}

Desde o ano de 1990, com a aprovação do Estatuto da Criança e do Adolescente (ECA), se reconhecem os direitos da criança e do adolescente e sua proteção, conforme se lê nos artigos abaixo:

Art. $3^{\circ} \mathrm{A}$ criança e o adolescente gozam de todos os direitos fundamentais inerentes à pessoa humana, sem prejuízo da proteção integral de que trata esta Lei, assegurando-se lhes, por lei ou por outros meios, todas as oportunidades e facilidades, a fim de lhes facultar o desenvolvimento físico, mental, moral, espiritual e social, em condições de liberdade e de dignidade.

Art. $4^{\circ}$ É dever da família, da comunidade, da sociedade em geral e do poder público assegurar, com absoluta prioridade, a efetivação dos direitos referentes à vida, à saúde, à alimentação, à educação, ao esporte, ao lazer, à profissionalização, à cultura, à dignidade, ao respeito, à liberdade e à convivência familiar e comunitária. Parágrafo único. A garantia de prioridade compreende: a) primazia de receber proteção e socorro em quaisquer circunstâncias; b) precedência de atendimento nos serviços públicos ou de relevância pública; c) preferência na formulação e na execução das políticas sociais públicas; d) destinação privilegiada de recursos públicos nas áreas relacionadas com a proteção à infância e à juventude.

5 Artigo 4: "É dever da família, da sociedade em geral e do Poder Público assegurar, com absoluta prioridade, a efetivação dos direitos referentes à vida, à saúde, à alimentação, à educação, ao esporte, ao lazer, à profissionalização, à cultura, à dignidade, ao respeito, à liberdade e à convivência familiar e comunitária".

6 Artigo 50: "Nenhuma criança ou adolescente será objeto de qualquer forma de negligência, discriminação, exploração, violência, crueldade e opressão, punindo, na forma da lei, qualquer atentado, por ação ou omissão aos seus direitos fundamentais". 
Os art. $3^{\circ}$ e $4^{\circ}$ do ECA asseguram às crianças e aos adolescentes os direitos fundamentais, a fim de que se desenvolvam física, mental, moral, espiritual e socialmente em condições de liberdade e de dignidade, sendo essa responsabilidade atribuída à família e às instituições para lhes assegurar os direitos arrolados na Lei 8.069/1990. A família deverá resguardar às crianças e aos adolescentes o direito à vida, à saúde, à alimentação, à educação, ao esporte, ao lazer, à profissionalização, à cultura, à dignidade, ao respeito, à liberdade e à convivência familiar e comunitária.

Entretanto, mesmo sendo obrigatória a defesa dos direitos das crianças e dos adolescentes, as notificações de violação desses direitos, segundo o Ministério da Saúde (1997, p. 17) são baixas. $E$ as provenientes dos profissionais das áreas de saúde, educação e bem-estar social indicam o seu pouco conhecimento e envolvimento, com o problema e com as instituições especializadas no atendimento de crianças vítimas de violência.

As diretrizes que orientam as ações e responsabilidades das escolas, art. 56 do ECA, deixam claro que essas instituições são lugares de proteção e defesa dos direitos das crianças e dos adolescentes, considerando que a criança deve ser percebida como cidadã de direitos. Partindo desse princípio, os/as professores/as deverão estar atentos à violação desses direitos, assegurando as obrigações contidas no art. 56 e seus incisos.

Art. 56. Os dirigentes de estabelecimentos de ensino fundamental comunicarão ao Conselho Tutelar os casos de: I - maus-tratos envolvendo seus alunos; II - reiteração de faltas injustificadas e de evasão escolar, esgotados os recursos escolares; III - elevados níveis de repetência. (ECA, 1990)

A temática violência doméstica contra a criança e o adolescente tem sido intensamente discutida e pesquisada muito mais pela área da saúde do que por outras áreas, especialmente a educação. É importante, nas práticas da escola e dos profissionais da educação, perceber a violência sofrida pelos/as alunos/as, tendo nessa identificação a possibilidade de enfrentamento e de proteção (LIMA, 2011).

A pesquisa realizada por Tiellet (2010), junto ao Conselho Tutelar (CT) do município de Cáceres/MT, no período de 2004 e 2005, evidenciou que do total de 1.333 registros de agressões contra crianças e adolescentes, $65.56 \%$ foram cometidos por parentes ou responsáveis. E no período de 2012 a 2014, em nova busca junto ao CT, a pesquisadora se deparou com o total de $2.443^{7}$ notificações de violação dos direitos das crianças.

Os dados apontaram que no município de Cáceres/MT, em média ocorrem dois registros de agressão contra crianças por dia, e é importante destacar que há ainda a cifra oculta, ou melhor, destaca Tiellet (2015), atos de violência contra a criança e o adolescente sem registro, desconhecidos, que não chegam ao conhecimento das autoridades por variados motivos, encobertos pelo medo, pela vergonha, impunidade e até mesmo pela aprovação da sociedade a determinados atos: palmadas e punições corporais em casa.

7 Fonte é o Conselho Tutelar. No ano de 2012 - 809 registros; 2013 - 859; e 2014 - 775 registros. 
Para Azevedo e Guerra (2009), o retrato emergente da violência contra a criança "revela um fenômeno extenso, grave, desigual e endêmico." (p.15). E que

há muitos casos não notificados e o número deles depende do tamanho do complô de silêncio, do qual muitas vezes participam profissionais, vizinhos, parentes, familiares e até a própria vítima. (AZEVEDO; GUERRA, 2009, p.17)

Mas, à medida que se tornam alarmantes os dados de violação dos direitos das crianças, podem significar que o aumento dos registros tenha ocorrido pelo reconhecimento e envolvimento da sociedade em prol da defesa e proteção da criança e do adolescente, segundo Chioquetta (2014), Azevedo e Guerra (2009), fruto dos mais de vinte anos da aprovação do ECA, embora ainda se proteja muito pouco as crianças e os adolescentes.

De acordo com o relatório de pesquisa de Tiellet,

[...] é possível constatar, através dos registros do Conselho Tutelar, que as violações de direitos podem ser estratificadas por faixa etária. Na violência física/agressão/lesão corporal/maus tratos/espancamentos a vítima tem entre sete e 15 anos; a violência sexual, estupro, abuso e assédio sexual ocorre entre 10 e 15 anos; e os registros de exploração sexual e aliciamento, entre os 13 e 18 anos de idade (TIELLET, 2015, p.22).

Os dados obtidos no Conselho Tutelar (CT) do município de Cáceres/MT foram organizados, por Tiellet (2015), segundo as violações de direitos da criança e dos adolescentes (ver Tabela I), não sendo incluídos os dados sobre a negligência. Embora seja a forma mais notificada no país, a negligência denuncia "algo que existe por trás da sociedade brasileira, que é, muitas vezes, o descaso com a vida em sua fase mais importante: a infância". (CHIOQUETTA, 2014, p.170).

Tabela I - Número de violações dos direitos das crianças no período de 2012 a 2014, registrados.

\begin{tabular}{|c|c|c|c|c|}
\hline Ano & $\begin{array}{c}\text { Exploração } \\
\text { sexual } \\
\text { Aliciamento } \\
\text { Abuso sexual } \\
\text { Estupro }\end{array}$ & $\begin{array}{c}\text { Violência física } \\
\text { Espancamento } \\
\text { Maus Tratos } \\
\text { Agressão Física } \\
\text { Lesão Corporal }\end{array}$ & $\begin{array}{c}\text { Dependência } \\
\text { química }\end{array}$ & $\begin{array}{c}\text { Ato infracional } \\
\text { práticado por } \\
\text { crianças }\end{array}$ \\
\hline 2012 & 39 & 33 & 06 & 01 \\
\hline 2013 & 96 & 83 & 15 & 02 \\
\hline 2014 & 51 & 106 & 05 & 05 \\
\hline Total & 186 & 222 & 16 & 08 \\
\hline
\end{tabular}

Fonte: Conselho Tutelar de Cáceres - Elaborada por TIELLET, Maria do Horto (2015). 
Segundo Videres (2013), a violência se manifesta de diferentes formas, isoladas e/ou sobrepostas. Em se tratando de violência doméstica, a família, considerada lugar de afeto e proteção, vem apresentando contradições no desenvolvimento do seu papel de cuidadora, quando violenta e provoca sofrimento biopsicossocial na criança e no adolescente.

Conforme evidenciado por Tiellet (2010), a violência na sociedade contemporânea é um desafio que, ao longo dos anos, vem sendo cada vez mais discutido e problematizado por diversos estudiosos, e é considerado, hoje, um problema social que se apresenta e se reflete no espaço escolar. Nas 2.443 violações registradas, no período de 2012 a 2014 , há 94 notificações encaminhadas pelas escolas, o que evidencia ainda a dificuldade do professor se envolver e cumprir seu papel de proteger as crianças e os adolescentes. Ainda há o receio por parte do professor de se envolver em questões familiares e o medo de represálias (TIELLET, 2015).

Considerando a amplitude do tema violência doméstica contra a criança e o adolescente, somado à responsabilidade, expressa no art. 56 do ECA, de os estabelecimentos de ensino comunicarem os maus tratos envolvendo alunos/as (inciso I), desenvolvemos uma pesquisa convergindo para o fenômeno da violência doméstica contra a criança em idade escolar.

Buscamos, nos relatórios do $6^{\circ}$ Batalhão da Polícia Militar de Cáceres/MT (Tabela II), o mapeamento dos bairros que concentravam maior registro de violência doméstica, e a partir dessas informações selecionamos aqueles que mais apresentaram casos de violência contra a criança e os adolescentes.

Tabela II - Número e tipificação das violações dos direitos das crianças e dos adolescentes no período de 2012 a 2014, nos bairros Mocidade Independente e Mocidade Alegre.

\begin{tabular}{|c|c|c|c|c|c|c|c|c|}
\hline \multirow[b]{2}{*}{ Bairros } & \multirow{2}{*}{$\begin{array}{c}\text { Natureza } \\
\text { das Viola- } \\
\text { ções }\end{array}$} & \multirow{2}{*}{$\begin{array}{l}\text { Quantida- } \\
\text { de }\end{array}$} & \multicolumn{2}{|c|}{ SEXO } & \multicolumn{4}{|c|}{ IDADE } \\
\hline & & & Masculino & Feminino & $\begin{array}{l}01-03 \\
\text { anos }\end{array}$ & $\begin{array}{l}04-06 \\
\text { anos }\end{array}$ & $\begin{array}{c}07-09 \\
\text { anos }\end{array}$ & $\begin{array}{l}10-12 \\
\text { anos }\end{array}$ \\
\hline \multirow{3}{*}{$\begin{array}{l}\text { Mocidade } \\
\text { Indepen- } \\
\text { dente }\end{array}$} & $\begin{array}{l}\text { Lesão } \\
\text { Corporal }\end{array}$ & 3 & \multirow{3}{*}{4} & \multirow{3}{*}{3} & \multirow{3}{*}{2} & \multirow{3}{*}{1} & \multirow{3}{*}{1} & \multirow{3}{*}{4} \\
\hline & Ameaça & 2 & & & & & & \\
\hline & Estupro & 2 & & & & & & \\
\hline & & & & & & & & \\
\hline \multirow{3}{*}{$\begin{array}{l}\text { Mocidade } \\
\text { Alegre }\end{array}$} & $\begin{array}{l}\text { Lesão } \\
\text { Corporal }\end{array}$ & 2 & \multirow{3}{*}{2} & \multirow{3}{*}{3} & \multirow{3}{*}{1} & \multirow{3}{*}{1} & \multirow{3}{*}{1} & \multirow{3}{*}{3} \\
\hline & Ameaça & 1 & & & & & & \\
\hline & Estupro & 3 & & & & & & \\
\hline \multicolumn{2}{|c|}{ TOTAL } & 13 & 6 & 7 & 2 & 2 & 2 & 7 \\
\hline
\end{tabular}

Fonte: Relatório da Polícia Militar - Elaborada por AUTOR, xxxxx da (2017) 
Em meio aos dois bairros ${ }^{8}$, denominados "Mocidade Alegre" e "Mocidade Independente", localizamos a Escola Municipal "Isabella9".

\begin{abstract}
A Escola é de alvenaria, possui 8 (oito) salas, sendo 6 (seis) salas de aula e as outras duas com funções compartilhadas, secretaria junto com a direção da escola e na sala dos/as professores/as funciona também a coordenação. $E$ da mesma forma que nos bairros ao redor, o espaço interno da escola, também é de chão batido. São 19 os/as professores/as assim distribuídos nas seguintes funções:17 (dezessete) professores/as, 1(um) Coordenador/a e 1(um) Diretor/a. Eles/as desenvolvem atividades didático-pedagógicas para 271 (duzentos e setenta e um) estudantes matriculados na Educação Infantil e no Ensino Fundamental no ano de 2015 (SILVA, 2016, p.27).
\end{abstract}

A tipificação das violações dos direitos das crianças e dos adolescentes nos bairros, nos conduziu a compreender o modo com o qual a escola que atende os dois bairros (Mocidade Independente e Mocidade Alegre) tem assegurado a proteção à criança e atendido as legislações pertinentes. Nesse aspecto, a percepção dos/as professores/as sobre a violência doméstica contra a criança é fundamental.

\title{
Metodologia
}

Embora tenhamos clareza de que os processos de vida são qualitativos, quantitativos e complexos, de modo que é difícil separar o qualitativo do quantitativo, desenvolvemos uma pesquisa ${ }^{10}$ qualitativa. Como abordagem usamos a fenomenologia, pois entendemos que a mesma descreve a realidade significativa, num exercício que abstrai e transcende a materialidade, apresentando a consciência de quem a experiencia, enfim, possibilita-nos compreender a percepção dos sujeitos.

Conforme Merleau-Ponty,

a percepção não é uma ciência do mundo, não é nem mesmo um ato, uma tomada de posição deliberada; ela é o fundo sobre o qual todos os atos se destacam e ela é pressuposta por eles. O mundo não é um objeto do qual possuo comigo a lei de constituição; ele é o meio natural e o campo de todos os meus pensamentos e de todas as minhas percepções explícitas. [...]. Quando volto a mim a partir do dogmatismo do senso comum ou do dogmatismo da ciência, encontro não um foco de verdade intrínseca, mas um sujeito consagrado ao mundo (MERLEAU-PONTY, 1999, p. 6).

8 Os nomes dos bairros são fictícios

9 Nome fictício.

10 O projeto foi submetido e aprovado pelo Comitê de Ética na Pesquisa (CEP) da Universidade do estado de Mato Grosso, pelo Parecer n. 1.226.004, e sob o número CAAE 47685215.7.0000.5166, e, desse modo, garantir o anonimato aos sujeitos que aceitassem participar da pesquisa. 
O fenômeno - para o qual direcionamos o olhar - é o da violência doméstica contra a criança, refletido na Escola Municipal "Isabella", localizada entre dois bairros da cidade de Cáceres/MT que apresentam índices elevados de boletins de ocorrência policial de violência doméstica se comparados a outros bairros da cidade. Assim, a pesquisa é um estudo de caso. Tem por objetivo tipificar a violência contra a criança em âmbito familiar e saber de que forma a escola trabalha com o problema.

Segundo Boemer (1994), a fenomenologia não parte de um problema, mas de uma interrogação, e, de acordo com Bicudo (2011), a interrogação manifesta as inquietações do pesquisador, ao mesmo tempo em que norteia os passos da compreensão e da interpretação, elementos estes que constituem a abordagem fenomenológica. A interrogação que norteia a pesquisa é: de que modo os atores escolares (coordenação pedagógica, direção), especialmente os/as professores/as, tomam para si a obrigatoriedade (dever) de cumprir o estabelecido no Estatuto da Criança e do Adolescente, isto é, o de proteger à criança vítima de violência domésticas?

Sabemos que, a filosofia fenomenológica incomoda porque implica num movimento muito difícil, o de estranhar o que está naturalizado, o óbvio. Se lança sobre o que é possível e como é possível conhecer. Esse método traz um aporte teórico que encaminha para a redução fenomenológica em termos práticos em uma pesquisa e a busca de conhecimento sobre as relações sociais:

fenomenologicamente, não se procede por amostra, mas sabemos que quanto mais sujeitos, maior será a variabilidade das experiências vividas a respeito do fenômeno situado. [...] É importante observar-se que o número de sujeitos ouvidos é definido pela repetição, nas descrições, de aspectos importantes ao fenômeno interrogado (BICUDO, 2011, p.56).

Para a escolha e a definição da quantidade de sujeitos usamos a técnica da "cadeia de informantes", ou "cadeia de referências para o recrutamento" de sujeitos que farão parte da amostra. "Diferente das técnicas tradicionais de amostragem, que buscam a independência entre os elementos da amostra, esse tipo de técnica faz uso justamente das relações entre as pessoas" (ALBUQUERQUE, 2009, p.12).

Nessa técnica, os sujeitos iniciais do estudo foram o/a diretor/a e o/a coordenador/a, indicando cada um/a deles/as um sujeito (professor/a) que, por sua vez, indicaram outros/ as e assim sucessivamente até termos alcançado o ponto de saturação, atingido quando os sujeitos indicados passaram a repetir os conteúdos já obtidos em entrevistas anteriores, sem acrescentar novas informações relevantes à pesquisa.

Os sujeitos entrevistados foram denominados sujeitos significativos, por se constituírem em um grupo de professores/as que, segundo seus pares, possuíam informações relevantes por terem envolvimento com o fenômeno pesquisado.

Ao final, obtivemos sujeitos que experienciaram o fenômeno da violência doméstica contra a criança em diferentes situações de tempo e espaço. Cada sujeito recebeu um co- 
dinome relacionado a flores (Iris, Hortência, Dália, Áster, Cravina, Camélia, Bromélia, Begónia e Azaleia), totalizando nove sujeitos significativos, cujas entrevistas possibilitaram, após as transcrições, destacar as unidades de significado e desvelar, através das experiências vividas por eles na Escola Municipal "Isabella", o modo de ser do fenômeno estudado, na região da pesquisa.

\footnotetext{
A fenomenologia é o estudo da experiência humana. É um método, segundo Oliveira (2014), que pretende cumprir duas exigências: a exploração do campo da consciência e os modos de relação desta com os objetos. Neste sentido, permite a compreensão por parte do/a pesquisador/a, da percepção dos sujeitos da pesquisa sobre o objeto de investigação e amplia a sua própria interpretação sobre o fenômeno e sobre o local da pesquisa (SILVA, 2016, p.24).
}

Para Bicudo (2011), toda linguagem é compreensão e interpretação da realidade. Compreender o objeto no mundo vivido é dar a ele a visibilidade, a possibilidade de ser visto." (SILVA, 2016, p.83). O primeiro passo para a compreensão foi a transcrição das nove entrevistas, ou seja, a passagem da fala para a escrita, de modo que os sujeitos significativos, segundo suas vivências, expusessem suas experiências, e, através delas, desvelassem o fenômeno. No método fenomenológico a compreensão é um dos seus passos compostos de dois momentos: um denominado de descrição, e o outro, de redução fenomenológica.

Através da descrição fenomenológica buscou-se o desvelamento da intencionalidade da consciência do sujeito. Para Bicudo (2011), "a descrição descreve o movimento dos atos da consciência. Ela se limita a relatar o visto, o sentido, ou seja, a experiência como vivida pelo sujeito. Não admite avaliação e interpretações, apenas exposição do vivido como sentido ou percebido" (p.45).

E o momento seguinte, na perspectiva fenomenológica de Merleau-Ponty, denominase redução fenomenológica, a qual objetiva ressaltar elementos essenciais, reduzindo-os em unidades de significado e de sentido para posterior interpretação.

A redução fenomenológica de Merleau-Ponty é constituída por dois passos, na descrição do método fenomenológico de Maria Aparecida Bicudo. O primeiro passo coloca em evidência sentidos; o segundo passo, definido por Bicudo (2011), é "estabelecer unidades de significado - reunimos as unidades de sentido, postas em frases que se relacionam umas com as outras, indicando momentos distintos, articuladas pelo/a pesquisador/a". Unidades de significado são, segundo Bicudo (2011), unidades que fazem sentido para o/a pesquisador/a tendo como orientação o que é perguntado.

O momento seguinte, denominado por Merleau-Ponty de interpretação fenomenológica, tem por objetivo revelar os significados implícitos ou ocultos na redução, possibilitando o desvelamento da visão de mundo do sujeito, em contraste com a visão de mundo do/a pesquisador/a. A Interpretação na fenomenologia é o momento em que o fenômeno é desvelado. 


\section{Resultados}

A fenomenologia tem um papel importante para elucidar a interpretação do mundo que se manifesta intencionalmente à consciência, evidenciando a experiência do sujeito. Conforme Rezende (1990), essa interpretação é construída numa dialética polissêmica, que se constitui no conflito de interpretações, tornando-se uma atividade necessária, pois esse caminho possibilita que a interpretação se aproxime da estrutura simbólica do fenômeno. Uma vez que a realidade não é um dado absolutamente, a realidade é construída, tratando-se de uma construção cognitiva, intersubjetiva.

Segundo Bicudo (2011) não é possível separar significado e sentido, "[enrolando-se] uns nos outros e conectando-se por fios de sentido que formam redes." (p.51).

[...] o pesquisador sintetiza as unidades de significado para chegar à estrutura do fenômeno e a sua essência. Nessa síntese, o pesquisador integra os 'insights'contidos nas unidades significadas transformadas em uma descrição consistente da estrutura do fenômeno. (BOEMER, 1994, p.91).

No estudo em pauta, destacamos algumas das unidades de sentido que desvelaram a percepção dos sujeitos significativos da Escola Municipal "Isabella" quando questionados sobre a percepção dos professores sobre a violência no entorno e os conflitos no interior da escola:

- Insegurança e medo do entorno da escola;

- Perfil dos/as alunos/as associado ao comportamento dos mesmos na escola;

- Tipologia da violência contra a criança e a atitude da escola frente à violência sofrida pela criança.

\section{Unidade de sentido: insegurança e medo do entorno da escola}

"[...] isso acontece quando veio essas casinhas pra cá porque antes a escola era maravilhosa. [...] nunca me deparei com uma situação conflitante como aparece nesta escola. Aqui as questões de violência sejam elas violências físicas, sejam elas violências verbais é muito grande. [...] alunos agressivos, família agressiva que dá medo, medo, medo [...]." (CRAVINA)

" [...] Cohab aqui do Bairro aonde tá as casinhas vieram muitos alunos diferentes e... vieram todos pra "cá" inclusive foi até um... um... um... tumulto porque não tínhamos, não tínhamos condições de receber todos esses alunos.[...], pais é viciados[...] país que vendiam drogas, [...] pai que bebia e batia "ni" mãe. Eram mães saiam à noite e... e... passavam a noite inteira, diz que, trabalhando. E aí[...] durante o dia ficava dormindo e os filhos vinham "pra" escola por conta própria [...]"(CAMÉLIA)

Ao evidenciarem o residencial localizado em um dos bairros do entorno da escola, os entrevistados destacam e delineiam o perfil dos moradores, estabelecendo uma associação velada entre a pobreza e a falta de educação, entre a pobreza e o crime e a imoralidade. 
Os sujeitos entrevistados acreditam que a maioria dos moradores do residencial localizado no entorno da escola é composta de famílias desestruturadas, as quais, apresentam diferentes configurações.

Mesmo diante da temática proposta - "violência doméstica contra a criança" -, os sujeitos significativos trataram de outras questões relacionadas à violência em que eles/as dão sentido à experiência vivida, colocando-se como também vítimas.

"[...] tem professora que infelizmente..., olha só, a ponto que chegou de: sair escoltado daqui da escola tivemos que chamar a polícia. [...] os professores não aguentavam mais esses alunos que ameaçavam." (ÁSTER)

A violência doméstica contra a criança tomou posição secundária diante do sentimento dos sujeitos perante a manifestação agressiva das crianças. Desvelam sentidos que se manifestam na violência do entorno da escola; na ameaça que sofrem de alunos/as e dos responsáveis por eles/as; na justificativa de que a presença masculina na direção da unidade educativa poderia diminuir a insegurança que sentem no interior da escola.

"[...] a secretária de educação pensasse em colocar uma pessoa dos sexo masculino na direção[...]"... talvez com essa mudança, botando uma pessoa do sexo masculino na direção, talvez né, dessa forma esse comportamento dos alunos, talvez mudassem." (ÁSTER) -

Na concepção dos sujeitos entrevistados, o residencial construído próximo à escola, no qual mora grande parte dos/as alunos/as que frequentam a escola, é o responsável pela insegurança e o medo que paira sobre a instituição escolar.

\section{Unidade de sentido: perfil associado ao comportamento dos alunos na escola}

As crianças e adolescentes que residem no residencial possuem um estereótipo na escola: são gangueiros, traficantes, ladrões e possíveis agressores, pois sendo elas vítimas de violência estão propensos a praticar em outros/as a violência por eles/as sofrida.

"[...] aluno ter grupos de gangues e já ter sido preso. [...] semana passada quarta, quinta-feira passada o filho dessa senhora deu um tiro brincando com uma garrucha, segundo o comentário que chegou aqui na escola. [...] o tiro acertou a boca de uma adolescente. [...] a violência eu percebo que vem de casa, seja a violência verbal ou a violência física" (CRAVINA)

"Os alunos de 10 a 11 anos já vivem no mundo do crime, roubam. Ele já estava traficando. [alunos] usam droga e vinham aqui pra escola drogados. Vinham pra escola tentando, usava drogas aqui na escola." (CAMÉLIA) 
[...] Alguns alunos bate nos pequenos, provoca, conta vantagem, [diz que] andando na rua de Trabuco na mão. Comenta que assaltou uma moça de moto. "[...] fazem graças com a cara da polícia." A psicóloga um dia comentou [que] a criança que é abusada [...] tem uma porcentagem [de] no futuro também ela abusar de uma outra criança. A gente fica preocupado com a questão da segurança também dos pequenos, né. [Eu] fico morrendo de preocupação. A gente fica[va] sempre de olho no banheiro, né. Nem Deus de deixar os pequenininho (sic) aí." (ÍRIS)

\section{Segundo Azevedo \& Guerra}

[...] aqueles adolescentes que sofreram maus-tratos familiares sofrem mais episódios de violência na escola, vivenciam mais agressões na comunidade e transgridem mais as normas sociais, fechando assim um círculo de violência. Eles também têm menos apoio social, menor capacidade de resiliência e uma baixíssima autoestima (AZEVEDO \& GUERRA, 2009, p.18).

Assim, seja pelo efeito do abandono em que vivem e/ou pelo ambiente de violência estabelecido tanto no bairro e pela indiferença ou invisibilidade que sofrem na escola a reação de alguns alunos, seja por comportamentos e atitudes que provoque nos professores o medo, associando-os a perfis criminosos. Dessa forma, é possível entender o pensamento hegemônico do coletivo de professores/as que nomeia as residências desses/as alunos/as de 'casinhas' e a cadeia de 'casão'. Segundo o/a professor/a, os/as alunos/as que moram nessas 'casinhas' possuem um destino já traçado: ser preso/a pela polícia, passar pelo Conselho Tutelar, ir para o Socioeducativo e depois para o 'casão' que é a Cadeia Pública. "É... assim, a gente aqui até brinca assim...sai do sócio... pegou a maioridade... vai pro "casão"[...] que é a cadeia[...]." (ÍRIS)

Ao evidenciarem o residencial como responsável pelos conflitos no interior da escola afetando os sujeitos entrevistados, eles delineiam o perfil dos moradores/as, estabelecendo uma associação velada entre a pobreza, a falta de educação, o crime, a imoralidade, o desrespeito e a bandidagem.

As evidências de perversidades sofridas dia após dia pelas crianças, conhecidas pelo conjunto dos/as professores/as da escola, mas permanecem na sombra e parecem não afetar a rotina da escola, a não ser quando iluminadas, em casos excepcionais, em que é humanamente impossível, não reagir.

“[criança] chegou aqui na escola queimado no rosto com Colher’ de Pau.” (CAMÉLIA.

"[...] uma "menininha" a "menininha" ela chegou toda com Hematomas só que aquele hematoma não era de pancada mais era de sugada...a...a...a criança, a menina nem era uma mocinha, ela poderia ter uns 13 anos ou 12 era menininha não tinha seio, não era uma mulher, era uma criança[...] aí a gente chamou a coordenadora chamou a diretora levou no banheiro [a menina]tinha marcas no corpo todo."(BROMÉLIA). 
Unidade de sentido: tipologia da violência contra a criança e a atitude da escola frente a essa violência

O/a professor/a é um observador privilegiado, pois conhece os seus/suas alunos/ as, e a escola é uma instituição com a qual a criança ou o adolescente que sofre violência doméstica pode contar. O art. 56 do ECA deixa claro que as escolas são lugares de defesa dos direitos e deveres, e também de proteção de crianças e adolescentes.

Os sujeitos entrevistados destacaram abuso sexual, estupro, maus tratos, negligência e violência física, o que coincide com os boletins de ocorrência registrados nos plantões policiais. Os sujeitos mencionaram casos que vivenciaram, apontando a tipologia da violência cometida contra a criança, sendo objetivos ao contarem os casos ocorridos e os quais presenciaram.

"violência sexual dentro da família. Agressor o avô" (ÏRIS)

"[...]um aluno dessa escola [sofreu] estupro, Aí, logo em seguida teve outra criança, aluno daqui da escola."(CAMËLIA)

"Um aluno defecava nas calças. Você sentia nele o tempo todo aquele mal cheiro de fezes e aquilo me chamou bastante atenção. Uma denúncia anônima de negligencia do Pai, no Conselho Tutelar, que o pai deixa as crianças sozinha em casa para ir trabalhar. Levaram essas crianças para a Casa do Menor nessa época e lá, segundo o relato desse aluno, ele foi abusado por outros menores. Ficamos sabendo também por outras vias né, [que a] história não era bem assim. Há desconfiança que o agressor foi o próprio pai, mas como provar e saber como que é realmente." [...]uma aluna também foi abusada por um padrasto e o próprio padrasto tava aqui na escola a gente vendo a mãe junto com ele disse que ia separar e tudo no final não separou e estava numa reunião de entrega de nota toda família reunida."[...] um aluno do terceiro ano é um aluno especial tem deficiência intelectual déficit de aprendizagem e hiperatividade, também chegou ao nosso conhecimento que ele foi abusado também na casa dele por um menor."(HORTÊNCIA)

"[...]pai agride filha em casa, mãe agride filha em casa, filho agride pai, agride mãe."[...] foi preciso mandar buscar a mãe um aluno problemático, e aí a mãe veio aqui esculhambou esse filho na nossa frente e ela ressaltava muito que ela não podia, se ela perdesse a bolsa família dela ele ia tomar uma surra. [...]confirmaram pra mim que quando sai o dinheiro da bolsa família a mãe está no bar bebendo e essa criança vem pra escola sem material e nós que temos que correr atrás do material para o aluno - borracha, caneta, lápis de cor porque e material básico para qualquer aluno ele não tem." (CRAVINA)

Embora conheçam suas obrigações frente ao ECA, saibam tipificar a violência sofrida por seus/suas alunos/as, a atitude dos sujeitos entrevistados da escola "Isabella" frente à violência doméstica contra a criança é preferencialmente de não envolvimento. 
"eu não enfrento mais porque eu também não consigo denunciar, sinceramente nem perco tempo" (CRAVINA).

"Nós não estamos mais querendo nos envolver nas questões familiares. [...] dar carinho te dar atenção de acolhê-los aqui pra ele sentirem amados aqui, mas aí hora que sai do portão pra fora já não cabe mais a nós." (CAMÉLIA).

"[...] assim nós mesmos enquanto profissionais, eu particularmente, eu nunca me coloquei a serviço dessas causas, assim diretamente. Você passa "pro" coordenador passa "pro" diretor. Depois a gente fica sabendo que o fulano de tal realmente teve maus tratos, você percebe, a gente sente até omissa nessa questão. Me sinto muito omissa em várias situações, era notório que eu observava só que dá aquele medo de você chegar e dizer que foi isso que aconteceu." (AZALÉIA).

O medo se apresenta como o principal responsável pelo recuo dos/as professores/ as na denúncia da violência doméstica vitimada por seus alunos. Eles se sentem solitários. Em ocasiões mais graves buscam apoio na direção da escola que, por sua vez, acionem o Conselho Tutelar, como instituição de proteção à criança e ao adolescente encontra-se despreparado materialmente (sem carro e mesmo local para abrigo) para atender as vítimas.

"[...] a coordenadora pedagógica passou o ano inteiro pedindo socorro lá no ConseIho Tutelar. Eles simplesmente falavam "pra" coordenadora que eles tinham problemas maiores pra resolver [...].” (CAMÉLIA).

"[...] alguns dos órgãos públicos, em especial, um que eu não vou mencionar, numa das ocasiões a escola solicitou a visita dele aqui "pra" nos ajudar [...] na época deixou a gente esperando nem um telefonema ficamos aqui, era uma reunião por volta das $17 \mathrm{~h}$ ficamos aqui até as $19 \mathrm{~h}$ aguardando até, cansamos de esperar." (HORTÊNCIA).

" [...] gente quando acontece casos assim é difícil porque você não tem um amparo e você não tem respaldo." (BROMÉLIA) -

"[...] a escola não consegue, é, resolver essa situação, ou professor diretamente é fica indeciso no sentido de como agir diante dessa criança [...] o professor às vezes, ele, não tem, é, o conhecimento, as vezes esse professor não tem essa experiência "pra" "tá" tentando resolver isso." (DÁLIA).

Assim, os/as professores/as experienciam de diferentes formas a fragilidade das instituições e a impotência de cada um frente a problemática, inviabilizando na prática o art. $5^{\circ}$ do ECA que expressa categoricamente que "nenhuma criança ou adolescente será objeto de qualquer forma de negligência, discriminação, exploração, violência, crueldade e opressão, punindo, na forma da lei, qualquer atentado, por ação ou omissão aos seus direitos fundamentais". 


\section{Considerações finais}

Para Merleau-Ponty, (1945/1999), ao revocar a essência na existência, o ser humano passa a ser compreendido a partir da sua relação com os fatos, no seu contato com o mundo, na sua relação com o tempo e o espaço no mundo vivido. A mediação com os fatos, isto é, para compreender a relação que se estabelece entre os professores da Escola Municipal "Isabella" e a violência doméstica a qual seus alunos são vítimas, ocorreu ao expor o seguinte questionamento: de que modo os atores escolares (coordenação pedagógica, direção), especialmente os/as professores/as, tomam para si a obrigatoriedade (dever) de cumprir o estabelecido no Estatuto da Criança e do Adolescente, isto é, o de proteger à criança vítima de violência domésticas?

Antes de responder à questão enunciada, apresentamos a tipificação a violência observada pelos sujeitos significativos, que foram escolhidos por indicação de colegas por terem eles presenciado e protagonizado, em fim por terem envolvimento com o fenômeno pesquisado.

A violência doméstica sofrida pelos alunos da escola é constatada, pelo olhar dos sujeitos significativos, e expressa pela negligência, pela violência física, pelos maus tratos, pelo abuso sexual e o estupro. Muitas relatadas por mães, pelas vítimas, tendo agressores/ as identificados/as, mas não são denunciados/as quer pela vítima, quer pelos/as responsáveis pela criança.

O lócus da pesquisa é a Escola Municipal "Isabella", localizada em meio a dois bairros com maior índice de violação dos direitos das crianças, onde ocorreu o maior número de casos atendidos pela Polícia Militar. Os bairros possuem iluminação pública precária, falta saneamento básico e parte do asfalto nas ruas. Também não dispõem de ginásio poliesportivo e nenhum espaço para crianças desenvolverem alguma atividade de esporte e lazer. A maioria das casas que compõem esses bairros são muito pequenas, sem varanda e boa parte não possuem muros que separam uma casa da outra.

A Escola Municipal "Isabella" é de alvenaria, possui 8 (oito) salas, sendo 6 (seis) salas de aula e as outras duas com funções compartilhadas, secretaria junto com a direção da escola e a sala dos/as professores/as funciona também a coordenação. E da mesma forma que nos bairros ao redor, o espaço interno da escola, também é de chão batido. Nesse espaço 19 (dezenove) professores/as efetivos assim distribuídos nas seguintes funções:17 (dezessete) professores/as, 1(um) Coordenador/a e 1(um) Diretor/a. desenvolvem-se atividades didático pedagógicas para 271 (duzentos e setenta e um) estudantes matriculados na Educação Infantil e no Ensino Fundamental.

Antes da criação do residencial, próximo da Escola, os professores não percebiam a violência extramuro.

"[...] percebemos depois que foi implantado esse residencial [...] começou... essas... ocorrer essas mudanças aqui na escola[...] são... casinhas né, que foram doadas pelo governo a famílias carentes. Critérios para essas famílias serem carentes ob- 
terem as casas foi ter uma criança ou uma pessoa deficiente especial, ter baixa renda ser mãe solteira. $E$ foi assim que se montou esse residencial. Essa mudança que teve aqui na escola foi por conta desse residencial. [...] esse monte de famílias desestruturada que foi colocada. Pegou a casa, obá "tou" indo "pra" minha casa. A maioria sobrevivi da Bolsa Família". (IRIS)

É nesse ambiente, segundo os sujeitos significantes, que se manifesta a violência doméstica contra a criança e o adolescente, associando aos moradores do residencial a violência, o tráfico de drogas e o crime e, alimentando o preconceito social sobre essa população.

Consta-se que os/as professores/as têm consciência de que a violência doméstica tem consequências em todos os aspectos da vida dos indivíduos que são vítimas daqueles que deveriam cuidá-los e protegê-los, entretanto, a violência sofrida pela criança para os sujeitos pesquisados, não afeta a escola, é algo externo pertencente ao âmbito privado.

Os entrevistados não percebem o fenômeno como algo que possa alterar o cotidiano, nem o clima escolar, muito menos os aspectos didáticos e pedagógicos relacionados a sua aula. Não estabelecem relação entre a violência que os alunos sofrem no âmbito privado de seus domicílios e os conflitos e a violência produzida no interior da escola, desconsideram que a violência gera violência inclusive colocando-os (professores/as) também como vítimas.

A violência doméstica a qual sofre o aluno, sai do anonimato quando a agressão se torna visível, de outro modo não se sentem, os sujeitos entrevistados, compelidos à tomada de ação, o medo e a impotência os paralisam. Eles não se sentem seguros para enfrentar as dificuldades e os transtornos resultante de uma denúncia.

Segundo os relatos dos sujeitos significativos da Escola Municipal "Isabella" a violência doméstica que sofrem alguns dos alunos é um drama, um problema familiar, do qual querem manter distância pela descrença nas instituições, e desconfiança de que elas possam proteger. $\mathrm{O}$ que põe em discussão o sistema de proteção à criança e ao adolescente que, conforme estabelecido pela Constituição Brasileira e pelo ECA, se constitui em uma rede formal de instituições e serviços que, sob parcerias, organizam-se para garantir a defesa e os direitos das crianças e dos adolescentes. Embora tenha o Brasil sido um dos primeiros países do mundo e o primeiro da América Latina a criar um estatuto que atenda as normativas internacionais no que diz respeito à proteção das crianças e adolescentes, proibindo e condenando a violência infantil, entretanto, ainda falta muito a ser colocado em implementado.

A escola e os/as professores/as não podem se sentir sós na proteção das crianças e dos adolescentes. Como afirma Elsen (2011), a escola, além de ser competente nas dimensões educativas, precisa reconhecer-se como um dos elos da corrente que defende os direitos à vida, à saúde e à cidadania das crianças, relacionando-se com as demais instituições, e, dessa maneira, fortalecendo a rede de proteção a crianças e adolescentes. 
O reconhecimento dos atos de violência doméstica sofridos pelos/as alunos/as são fatos que foram trazidos pelos/as professores/as quando instigados pela entrevista, não como fato reconhecido que exige acolhimento por parte da escola, mas como estreitamento e mescla de sentimento de insegurança, medo, solidão e indiferença dos/as professores/ as frente ao entorno e no interior da escola. O que os faz se resignarem a impossibilidade de ajudar. Percebe-se a solidão dos/as professores/as frente ao problema. A solidão como atitude individualizada, sem o envolvimento dos pares na construção de respostas ao problema constatado, tanto de enfrentamento solitário, quanto de omissão.

O medo, insegurança, a solidão e indiferença dos/as professores/as da Escola Municipal "Isabella" são componentes, resultantes e desvelados do fenômeno da violência doméstica que atinge seus alunos, considerados motivos que limitam o envolvimento dos/ as professores/as, de modo geral, nos casos experienciados pelos/as alunos/as por serem estes/as filhos/as ou parentes de moradores/as do residencial próximo à escola e por estar associado, na escola, aos moradores do residencial termos como: violência, tráfico de drogas, fome, pobreza e famílias desestruturadas.

O outro objetivo da pesquisa foi saber de que forma a escola trabalha com o problema da violência doméstica, este relacionado ao questionamento que motivou a pesquisa, isto é, de que modo os atores escolares (coordenação pedagógica, direção), especialmente os/as professores/as, tomam para si a obrigatoriedade (dever) de proteger à criança vítima de violência domésticas.

Na Escola Municipal "Isabella", lócus da pesquisa constata-se uma certa dificuldade tanto dos/das professores/as quanto da coordenação pedagógica e direção de tratarem do fenômeno. Os professores preferencialmente optam por apresentar o problema para a direção da escola, que por sua vez dirige-se ao Conselho Tutelar. Ao mesmo tempo, foi possível evidenciar que para os sujeitos significativos entrevistados/as a violência contra eles/as (professores/as) merece também cuidados e proteção por parte das autoridades e instituições da administração de ensino e da segurança.

No âmbito do contexto escolar pesquisado, as ações para o enfrentamento do problema da violência no entorno ou no interior da escola seja da violência doméstica contra crianças e adolescentes, seja dos conflitos e violências no interior da escola, não foram mencionadas pelos sujeitos entrevistados, nenhum projeto desenvolvido pela escolas e pelas instituições constituídas, e assim, quando estas são chamadas para agir suas ações são ineficazes e sem efeito prático. 


\section{REFERÊNCIAS}

ALBUQUERQUE, Elizabeth Maciel de. Avaliação da Técnica de Amostragem "Respondent-Driven Sampling" na Estimação de Prevalências de Doenças Transmissíveis em Populações Organizadas em Redes Complexas. 2009, 99f. Dissertação. (Mestrado em Ciências na Área de Saúde Pública) - Programa de Pós-Graduação em Ciências na área de Saúde Pública da Fundação Osvaldo Cruz. Rio de Janeiro, RJ. 2009.

BICUDO, Maria Aparecida Viggiani ; MOCROSKY, L. F. ; BAUMANN, A. P. P . Pesquisa qualitativa

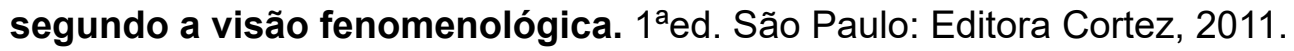

BRASIL. [Constituição (1998)]. Constituição da República Federativa do Brasil Brasília, DF, Senado Federal, 1998.

BRASIL. [Lei n 8.069, de 13 de julho de 1990]. Dispõe sobre o Estatuto da Criança e do Adolescente. Disponível em: http://www.planalto.gov.br. Acesso em: 20 set. 2012.

BRASIL. [CONANDA] - Conselho Nacional dos Direitos da Criança e do Adolescente. Encontros de articulação do CONANDA com os Conselhos Tutelares. Brasília,DF, 2000.

CHILDHOOD BRASIL. Violência sexual contra crianças e adolescentes: novos olhares sobre diferentes formas de violações. 2004. Disponível em: http://www.childhood.org.br/wp.../violencia-sexual_childhood_final_ISBN.pd. Acesso em 21.jun.2015. Acesso em: 7 jul.,2017

CHIOQUETTA, Rafaela Dotti. Violência doméstica contra crianças e adolescentes: o berço do crime. Revista Virtual do Laboratório de Estudos da Violência e Segurança - LEVS/UNESP-Marília, edição 13, p. 169-179, maio, 2014.

ELSEN, Ingrid; PRÓSPERO, Elisete Navas Sanches; SANCHES, Elizabeth Navas; FLORIANO, Cristiano José; SGROTT, Bruna Cristina. Escola: Um espaço de revelação da violência doméstica contra crianças e adolescentes. In Revista Psicologia Argumento, jul/set, 2011, p.303-314.

FISCHER, Beatriz T. Daudt; WEIDUSCHADT, Patricia . História oral e memória: aportes teórico-metodológicos na investigação de tragetórias docentes. In: Beatriz Terezinha Daudt Fischer; Márcia Ondina Vieira Ferreira; Lúcia Maria Vaz Peres. (Org.). Memórias docentes: abordagens teórico-metodológicas e experiências de investigação. 1ed.São Leopoldo; Brasília: Oikos; Liber Livro Editora, v.1, 2009.

GUERRA, Viviane Nogueria de Azevedo. Violência de pais contra filhos: a trajetória revisitada. 5 ed. São Paulo: Cortez, 2005.

AZEVEDO, Maria Amélia; GUERRA, Viviane N. de Azevedo. Violência doméstica contra crianças e adolescentes: um cenário em (des) construção.2009. Disponível em http://www.unicef.org/brasil/ pt/cap_01.pdf. Acesso em: 05.fev.,2016.

LIMA, Marsiléia. Brasil de Percepções de professores do ensino fundamental sobre violência doméstica contra crianças e adolescentes: estudo sobre o processo de notificação em uma escola pública do município de Manaus - AM. 2011. 91f. Dissertação (Mestrado em Serviço Social) - Pós-graduação em Serviço Social da Pontifícia Universidade Católica do Rio de Janeiro, 2011. 
MERLEAU-PONTY, Maurice, 1908-1961. Fenomenologia da percepção. Tradução Carlos Alberto Ribeiro de Moura. São Paulo: Martins Fontes, 1999.

ONU. Organização das Nações Unidas. Declaração Universal dos Direitos Humanos da ONU. Disponível em. <http://www.comitepaz.org.br/download/Declara\%C3\%A7\%C3\%A30\%20Universal\%20dos\%20Direitos\%20Humanos.pdf> Acesso em: 10 de jul.,2014.

ONU, Organização das Nações Unidas. Um rosto familiar: A violência na vida de crianças e adolescentes. Disponível m: <https://www.unicef.org/brazil/pt/EVAC_SummaryBrochure_Portugues_Final. pdf> Acesso em:03 nov.,2017.

PINHEIRO, Paulo Sérgio. Estudo das Nações Unidas sobre a Violência Contra Crianças. ONU,2006. Disponível em: <https://www.unicef.org/brazil/pt/Estudo_PSP_Portugues.pdf> Acesso em: 03 ago., 2017.

REZENDE, A. M. de (1990). Concepção Fenomenológica da Educação. Coleção Polêmicas do nosso tempo, v. 38. São Paulo: Cortez / Autores Associados

SILVA, Maria Aparecida da. XXXXXXXX

TIELLET, Maria do Horto Salles; FERREIRA, José Ferreira. ANTUNES, Maria da Penha. Conflitos e violências em escolas públicas estaduais em uma região de fronteira, Cáceres/MT: a percepção dos professores. 2010, 146f. [Relatório de Pesquisa]. Universidade do Estado de Mato Grosso, Cáceres/MT: FAPEMAT,2010.

TIELLET, Maria do Horto Salles. Adolescentes em conflito com a lei e suas trajetórias escolares. 2015. 25f. [Relatório de Pesquisa]. Universidade do Estado de Mato Grosso. Cáceres/MT, 2015.

WEBER, Maria Aparecida Lissarassa. Violência doméstica e rede de proteção: dificuldades, responsabilidades e compromissos. 2005, 125f. Dissertação. (Mestrado em Psicologia) - Programa de Pós-graduação em Psicologia do Centro de Ciências da Vida da Pontifícia Universidade Católica, 2005. 